Title: How do foster carers manage the oral health of children in foster care? A Qualitative Study.

Authors: Muirhead $\mathrm{V}^{1}$, Subramanian S.K $\mathrm{K}^{1,2}$, Wright $\mathrm{D}^{3}$, Wong F.S.L ${ }^{1}$

1) Institute of Dentistry, Barts and the London School of Medicine and Dentistry, Queen Mary University of London

2) Hospital Sultanah Aminah, Paediatric Dental Department

3) Public Health England, London Centre and Region 


\section{Objectives}

This qualitative study explored how the foster family environment influenced children's oral health. It also aimed to better understand foster carers' oral health knowledge, attitudes and experiences of managing foster children's oral health behaviours and oral health care.

\section{Methods}

An Interpretative Phenomenological Analysis (IPA) study design was used to recruit a purposive sample of foster carers in Tower Hamlets, UK from a range of backgrounds (maximum variation sampling). Participants were aged 21 years and older and provided full-time foster care for children for a minimum of one year. The foster carers took part in focus groups that were audio-recorded and transcribed verbatim. Data analysis followed a five-step IPA process, which included reading the transcripts, note-taking, identifying emerging themes, connecting related themes and writing up the final themes. Iterative data gathering and analysis continued to reach thematic saturation.

\section{$\underline{\text { Results }}$}

Three focus groups were conducted, involving a total of 12 foster carers. Eight of the 12 participants had fostered children for more than 10 years and they were currently fostering 22 children aged five to 18-years-old. Four themes emerged from within the context of the supportive and nurturing foster family environment that described how foster carers' responded to and managed the oral health of their foster children. Foster carers had adopted an oral health caregiving role, "in loco parentis" responding to the poor oral health of their vulnerable foster children. They were hyper-vigilant about establishing and monitoring children's oral health routines and taking their children to see a dentist; these were seen as an integral part of being good foster carers. They were knowledgeable about the causes of children's oral ill-health, gained from their own dental experiences and from looking after their own children. Foster carers had experienced tensions while adopting this oral health caregiving role with dentists who had refused to see younger children. Foster carers had also experienced tensions with teenage foster children who questioned their parental authority and legitimate right to set rules about smoking and healthy eating.

\section{$\underline{\text { Conclusions }}$}

This is the first study to explore foster carers' oral health perspectives and the foster family environment within the oral health context. It highlights the unrecognised and important role that foster carers have in improving the oral health of vulnerable children. Further research is needed to explore the relationship between foster carers and dentists and to support the development of health and social care interventions to improve foster children's oral health. 


\section{Introduction}

Foster care is defined as "situations where children are placed by a competent authority for the purpose of alternative care in the domestic environment of a family other than the children's own family that has been selected, qualified, approved and supervised for providing such care"1. Foster care is a global phenomenon ${ }^{2-5}$. Approximately 400,000 children were in foster care in the U.S in 2015. More than 40,000 foster children lived in Canada in 2011 and 43,009 foster children lived in Australia in $2014^{6,7}$. An estimated one million children in the European Union (EU) (one percent of the EU child population) resided in alternative foster family arrangements in $2009^{8}$. Approximately 50,000 children lived in foster placements in England in 2016, equating to one in 200 of the total child population9. Moreover, England has seen a nine percent increase in the number of children being fostered over the past five years ${ }^{9,10}$. The vast majority of foster children in England live in nonkinship (non-relative) foster families ${ }^{11}$. Fostering arrangements range from interim or short-term emergency placements to long-term fostering, where children remain with foster families until they reach adulthood ${ }^{11}$. Seventeen percent of five to 18-year-old foster children in England had lived with the same foster family for more than five years in $2013^{12}$.

Physical abuse, neglect and family disruption are the most common reasons for children being placed in foster care ${ }^{6,9,13}$. Although foster children suffer from the same health problems as children living in other family settings, they often enter the care system in a poorer state of health because of poverty, abuse and neglect ${ }^{14-16}$. Family adversity has long-lasting effects: foster children consistently report poor educational, psychological and health outcomes ${ }^{17-19}$. In the UK, children in care were more likely to have experienced physical, mental and sexual health problems than their peers ${ }^{20}$. Foster children also have poor oral health, reporting a high prevalence of untreated dental caries, periodontal diseases and traumatic dental injuries ${ }^{21-23}$. Unhealthy lifestyles could be one possible explanation for these. Children in care were four times more likely than children living in other households to smoke, drink and use drugs ${ }^{24}$. Casey et $\mathrm{al}^{25}$ also described emotional and problematic eating behaviours that were prevalent in pre-teen foster children in Australia; these included overeating, binging, and hoarding foods.

Parents play an important role in establishing and maintaining children's oral health behaviours through their beliefs ${ }^{26}$, role modelling ${ }^{27}$, parenting self-efficacy ${ }^{28}$ and parenting style ${ }^{29}$, yet few studies have explored foster carers' parenting styles or examined the foster care environment in the context of children's health ${ }^{30}$. Lipscombe et $\mathrm{al}^{31}$ suggested that an authorative parenting style that involved explaining rules and behaviours and setting boundaries was the style that foster children were most able to adapt to. However, foster carers have also described the challenge of having a dual 
role as carers and employees, which could make it more difficult for them to establish and maintain children's oral health routines ${ }^{32,33}$. A qualitative study by Rees et $\mathrm{al}^{34}$ also described conflicts between carers and foster children surrounding meal times and food choices. Legal care orders restricting the parental responsibilities of foster carers mean that they cannot provide medical consent for dental and medical treatment ${ }^{35}$. This can create confusion and barriers to children accessing and receiving health services $^{36,37}$. Foster carers' own knowledge, attitudes and oral health behaviours could also be important, given that studies have shown significant associations between parents' attitudes, and oral health behaviours (such as tooth brushing, dietary habits and dental visits) and their children's attitudes and oral health behaviours ${ }^{38,39}$, yet no published studies to date have explored foster carers' oral health attitudes or knowledge.

Developing evidence-based effective oral health improvement interventions for foster children requires a deep understanding of the role and experiences of foster carers in managing foster children's oral health. Qualitative research uses an inductive and interpretivist paradigm, which is well suited for exploring complex health and social care issues ${ }^{40,41}$. This qualitative study aimed to tackle this important research gap by addressing three research questions: (1) how does the foster family environment influence the oral health of foster children; (2) what knowledge and attitudes did foster carers have about children's oral health; and (3) what were foster carers' experiences of managing their foster children's oral health behaviours and dental care?

\section{Methods}

This qualitative study was part of the mixed methods "Let's Talk about Teeth" dental health project carried out in 2014-15 in Tower Hamlets, $\mathrm{UK}^{21}$. The UK Social Care Research Ethics Committee (SCREC) granted ethical approval for this study (REC: 14/IEC08/0003).

This study used an Interpretative Phenomenological Analysis (IPA) study design to explore foster carers' experiences and how they made sense of these experiences in their own family context ${ }^{42}$. IPA also enabled foster carers to integrate their beliefs, memories and experiences with different children throughout their fostering career ${ }^{43}$.

This study adopted a social constructivist perspective. This paradigm recognises that foster carers' construct their knowledge and experiences within their own social, political, and cultural milieu ${ }^{44}$. Using this theoretical perspective allowed further exploration of the interrelationships between foster families and foster children's birth families. Foster carers were able to share and reflect on their varied encounters, describing common and disparate experiences. The research team included paediatric and 
community dentists, qualitative researchers, and public health consultants with support from social workers.

Situating this qualitative study in Tower Hamlets (an inner city multi-ethnic deprived area in London, UK) allowed us to explore the myriad socioeconomic and cultural influences that shape the fostering environment ${ }^{45}$. The Tower Hamlets Social Care department was the local government body responsible for the 225 foster children and 115 foster carers registered in 2014-2015.

The participants were registered Tower Hamlets foster carers, aged 21 years and older who provided full-time foster care to children aged zero to 18 years for a minimum of one year.

Carrying out health research with social care organisations can be very difficult ${ }^{46}$. Foster carers were a hard to reach group, which meant that the research team spent six months engaging with social workers and foster carers before starting the study. The research team also made early contact with foster carers in the Foster Carers Association and support groups while designing the study to explain the reasons for doing the study, to pilot the topic guide and to identify the most effective recruitment strategies. Based on their feedback, three approaches were used to recruit participants facilitated by a gatekeeper from the Fostering Development Team. These were: sending emails and postal invitations to all foster carers; attending monthly foster carers support group meetings to directly recruit foster carers; and posting a recruitment flyer on the internal fostering website.

Foster carers who contacted the research team expressing an interest in participating completed a short background questionnaire. This questionnaire was used to purposively select foster carers using maximum variation sampling to capture a wide range of perspectives from foster carers from different ethnic backgrounds, genders, and experiences of foster caring ${ }^{47}$.

Focus groups were used, to allow participants to share their experiences of foster caring, identify commonalities, and recognise, and challenge disparate experiences and attitudes. Although originally developed for in-depth interviews, IPA has been adapted for focus groups ${ }^{48}$.

The focus group discussions took place in March-May 2014 in a private room at the Local Government headquarters, and facilitated by a trained and experienced health and social care qualitative researcher (VM). The focus groups were inductive, interactive and non-hierarchical, where the facilitator encouraged open, equal and empathic dialogue between the foster carers ${ }^{49}$. The piloted topic guide was guided by the IPA approach. Foster carers were first asked questions about the "essence" or phenomenon of being foster carers, where participants gave their personal accounts 
of what it meant to be foster carers. Probing questions then captured their various lived experiences and their family encounters with foster children (research question 1). Further probing questions explored their knowledge and attitudes and how foster carers made sense and managed different aspects of foster children's care, including providing social, emotional, physical, mental and educational and health support (research question 2 and 3). The focus groups each lasted one to $1 \frac{1}{2} 2$ hours.

Sample size requirements for qualitative research are not based on sample size calculations but on thematic saturation ${ }^{50}$. Data gathering and analysis were concurrent, and recruitment continued until no new themes emerged from the data to reach thematic saturation.

\section{Data analysis}

The focus groups were audio-recorded and transcribed verbatim. Data analysis followed a five-step IPA process using NVivo 10 software ${ }^{51}$ : (i) close reading of each transcript for familiarisation; (ii) note taking to identify emergent themes; (iii) identifying connected and related themes (superordinate and subthemes); (iv) generating a final table of themes for all transcripts and (v) producing a written account. Two female researchers (VM, SKM) coded the transcripts and reached consensus about the codes and the emerging themes. Rigour and trustworthiness was established by revisiting issues and requesting clarification during the course of the focus groups, sharing the interpretations with foster carers (member-checking) after data analysis, and by triangulating interpretations through peer scrutiny and re-briefing among the research team ${ }^{52}$.

\section{Results}

Three focus group interviews were conducted involving 12 foster carers to reach thematic saturation. Four foster carers participated in each focus group. Eleven of the 12 participants were female and were aged between 45 years and 60 years of age, which reflected the age and gender profile of foster carers in Tower Hamlets (Table 1). The ethnic background of the participants was Asian (50\%), Black Caribbean (33\%) and Black African (17\%). The participants were long-term foster carers; eight of the 12 carers had fostered for 10 years or more. All of the foster carers were currently fostering children. Three-quarters of the foster carers were currently fostering one or two children and they were collectively currently fostering 22 children (Table 1). Most of the children who were being fostered were aged between five and 16-years-old.

Four themes emerged from the focus groups: (1) foster carers' oral health caregiving role "in loco parentis"; (2) foster carers' own knowledge, attitudes and dental experiences influencing the 
management of foster children's oral health; (3) tensions between dentists and foster carers adopting an oral health caregiving role; and (4) tensions between teenage foster children and foster carers adopting an oral health caregiving role. We will first describe the fostering environment and participants' perspectives of foster children because this not only addresses the first research question but also provides the context for understanding how foster carers managed the oral health of their foster children (research question 2).

\title{
The Foster Family Environment
}

The foster family environment was shaped by foster carers' motivations for fostering, their own fostering experiences and how they and their families responded to the children who lived with them often for many years. The reasons for fostering were pluralistic. Most foster carers expressed altruistic reasons for fostering, feeling passionate about helping children in need. Some foster carers decided to foster for practical reasons such as having the space to accommodate additional children in their home or as a second job. Friends and ethnic community members were also positive influences. The illustrative quotes is cited in the textbox below.

\begin{abstract}
"Well I decided to foster even though I have five children of my own but also if I have to get a bigger house I would like to do that, so I did. So I got my bigger house for the children and I thought let me go into fostering because I heard about a friend who was fostering and she was talking about it and I thought that sounds really quite good. So I thought let me go for it and I did and I found it very rewarding, interesting, all the different ethnicity, all different ages and you know. It's really terrific, I enjoy it." (Focus group 1)
\end{abstract}

Participants described fostering as a family experience, supported and involving the whole family including extended family members. Foster children often became inextricably rooted in the family, treated as family members and forming close attachments with the foster carers' own children as illustrated below.

"Everything. You're everything to them. You're their family. You're their friend. You're their guardian angel. You're a referee. You're everything to these children. And the best thing, you're giving them a family home. They're being a part of your family. They're looking at your sons or your extended family as their own for a while." (Focus group 3) 
The foster carers described the rewards that they and their families had experienced from fostering. They enjoyed seeing foster children progress and develop. They happily described the changes that they had witnessed in their foster children and took full credit for these changes.

"I enjoy the changes I see in the child when they come to me. One child stayed with me three years; when he came to me he was six and he couldn't say a word because he can't speak. He had a speech problem. When he left me he was talking like a parrot because every time he said something I correct it for him and he was like talking really well when he left me and that really makes me happy. So when you see changes and you see them having confidence, gaining confidence and all of that. That really makes me happy. (Focus group 2)

\section{Foster children as a vulnerable group}

Foster children entered this supportive, nurturing and facilitative fostering family environment in a vulnerable state, which foster carers' recognised and vividly described. Carers recalled foster children who had suffered from general neglect and abuse, affecting their physical, social and emotional wellbeing when they first entered care.

"I remember I had two children, they had no immune system, they were very young, they were ill every single day, coughs, vomit, everything. And I couldn't even give them an ice cream because they'd get a cough and they'd end up with a chest infection. But by the time they left after 18 months, I remember taking them to the seaside and they played. They didn't even get a cough or a cold. I thought that's because I've built up their immune system." (Focus group 3)

"I had a girl once, about three years ago. She was about eight and she was emotionally abused and neglected. She wouldn't talk, just quiet. I gave her a good clean-up. Her hair is very thick, and when I washed it. It's hard to comb. So I used the blow dryer and blow dry it out." (Focus group 3)

Foster carers also described children who had poor oral health when they first entered care. Dental caries was the most commonly experienced dental problem. Some children had no tooth brushing habits when they first arrived in the foster home, while others had never seen a dentist before.

"Okay, well there is this one when she came to me, her teeth were really bad. They had stains, which I was thinking was a disease or something. When I took them to the dentist, the dentist said it's because she doesn't brush her teeth." (Focus group 1)

"No. I mean, the sibling group I've got at the moment, I think is the worst case that I've had. The eldest, he came to me, he turned six on his next birthday the following month. He had the most awful teeth, and it's the first time that he needed to have six extractions under anaesthetic. He had never been to a dentist." (Focus group 2)

Many foster children were used to having either no consistent meal patterns or diets composed of high sugar snacks, fizzy drinks and sweets before they came into care. Foster carers spoke about 
foster children who had had episodes of binge and emotional eating and night-time snacking. Some foster carers had teenage foster children who smoked and who had started smoking at an early age

\begin{abstract}
"Yeah, lollipops in their mouths all the time. The [birth] father used to bring them home, you know those big bags of lollipops? And sometimes, I feel bad about it but I used to hide them. When I used to put them in the boot, I said "oh, I must have left it at the contact visit" because they used to remember what the [birth] parents used to give them. So kids would say "my mum gave this and my mum gave that" and I had to say "look, your social worker, [Social Worker's Name] said you're not allowed that because they're not good for you." (Focus group 3)
\end{abstract}

"Before he came to me he started and then he stopped for about a year and a half when he came to me, and then when his sister joined him, he started again. They do smoke, brother and sister used to smoke but they moved the sister away. Now the brother is still with me. But his, I mean yesterday he told me he's going to quit. He's going to try to. I took him to my doctor and they referred him to a clinic, he didn't want to talk to the clinic." (Focus group 2)

It was from the context of the supportive and nurturing foster family supportive environment that four themes emerged that described how foster carers' responded to and managed the oral health of their foster children who they perceived to be vulnerable from multiple fronts (research question 3). The concept map shown in Figure 1 depicts the four themes detailed in the subsequent sections.

\title{
Theme 1: Foster carers" oral health caregiving role "in loco parentis"
}

Foster carers shared their experiences of establishing daily tooth brushing routines for their foster children. They closely monitored their children's tooth brushing regarded as just another part of keeping their children clean and washed. They saw this oral health caregiving role as an integral part of being foster carers "in loco parentis," looking after their children's physical, social and emotional wellbeing (Research question 3).

\footnotetext{
"But I make sure they brush their teeth twice a day. Morning and evening before they go to bed. They have to, every single day they have to. So yes and making sure those sugar things, even if they've been eating the whole day before they go to bed they have to brush their teeth, that's what I do." (Focus group 1)

"No, no. They don't wash their face. They don't really like to have a wash or anything. So I have to make sure they have their shower tonight and in the mornings. They should brush them at night really. That's the most important, nights. They still don't do it, so in the mornings I make sure before they leave the house the bathroom door is open and I watch them brush their teeth." (Focus group 3)
}

They recalled using different strategies to change foster children's unhealthy eating patterns. These included cooking meals, bargaining and incorporating ethnic foods from foster children's cultural background into the family meals. Foster carers were often hyper-vigilant about monitoring their children's diets and tooth brushing routines. They purposely restricted foster children's sugar intakes, replacing sugary snacks and junk foods with freshly prepared meals or fruits. 
"Every day I get up I explain to her and she had a lot of sweet things and I cut down on buying her sweet stuff. I tell her she need to." (Focus group 2)

"I've tried to cook in a different way, sometimes they will eat some other things but they don't like vegetables. I will buy fruits; they will just be looking at it. So I cut them up." (Focus group 1)

Another aspect of their caregiving role was overseeing their foster children's dental visits (Research question 3). Foster carers routinely took their children to see either their own dentist or their foster child's own dentist. They had had no consent problems. Dentists were the main source of oral health information rather than social workers or other health professionals.

"I make sure that I take them to the dentist every six months or you know if there is a problem, which I have never had, after a few months but I make sure they brush their teeth twice a day." (Focus group 1)

Theme 2: Foster carers' own knowledge, attitudes and dental experiences influencing the management of foster children's oral health

Foster carers had positive oral health attitudes and they were quite knowledgeable about the causes and consequences of poor oral health (Research question 2). They attributed dental caries to high sugar diets and inadequate tooth brushing. They had acquired this knowledge from their own negative and positive dental care experiences. They had also gained knowledge from caring for their own birth children and they tried to adopt similar strategies with their foster children.

"When I had my [own] kids they were always at the dentist, I used to take all five of them straight to the dentist altogether at once, so they have perfect teeth I must say, my children have; and for myself. I go to the dentist as well, funnily enough, I am going there later on because I was eating something and I broke my tooth." (Focus group 1)

Theme 3: Tensions between dentists and foster carers adopting an oral health caregiving role

Despite their good oral health knowledge, foster carers still had questions, particularly about accessing dental services and preventing dental caries. Some of their questions and uncertainties stemmed from their actual contact with dentists. They had received some inconsistent messages from dentists making it more difficult for them to give oral health advice, particularly about added sugars in teenage diets. This tension was also evident when it came to taking younger children for their first dental visit. Foster carers described being frustrated with dentists who refused to see younger children, conflicting with statutory guidance ${ }^{53}$. 
"You go to the dentist and then they're eating lots of sweets, they're not brushing their teeth, the dentist is saying to them "oh your teeth are lovely." The dentist needs to say although you're fine now, if you don 't brush your teeth this and this." (Focus group 3)

"Yeah, I took both children, one was four, one three. And he took the four one and he said to me she's too young. I said can you just look at her teeth anyway? She was three. Yeah, he said to me she's too young. I said to him can you just look at her and she wouldn't open her mouth. He said to me this is the problem with younger ones, you know? They don 't want to open their mouth and they're too young to understand. I wasn't really happy about that. They should find a way." (Focus group 3)

Theme 4: Tensions between teenage foster children and foster carers adopting an oral health caregiving role

Not only did foster carers describe tensions with dentists, they also spoke about the tensions with their own teenage foster children while adopting their oral health caregiving role. Teenage foster children sometimes questioned their parental authority when they tried to help them to quit smoking or stop eating unhealthy foods brought into the home.

"Yes when we talk about it she said no, her parents told her to stop it, she said 'nobody can stop me'. It's her life so we are still talking early days. "(Focus group 1)

"They smoke outside. We told them not to smoke. But it's not many. I think it was one girl I had who smoked." [She was) 15. She respected my home, so I respected her and I explained to her how dangerous it was. No, I tried but they wouldn't listen. They do not listen to you, do they?" "Who are you? You're not my mum. Telling me what to do", something like that." (Focus group 3)

\section{Discussion}

This is the first study to date to explore foster care in the context of oral health, identifying novel findings. Foster carers had adopted an oral health caring role, "in loco parentis" responding to the poor oral health of foster children. They were hyper-vigilant about establishing and monitoring children's oral health routines, which were seen as an integral part of being good foster carers. The hyper-vigilance displayed by foster carers could be mirroring the authorative parenting style reported in previous studies.

Lipscombe et $\mathrm{al}^{31}$ also described differences in the parenting styles adopted by foster carers and birth parents. These differences included foster carers appreciating their foster child's background and previous parenting, being aware of negative and traumatic experiences, coping with difficult behaviours, adapting to their child's learned defensive actions and forming attachments with the wider foster families (reflective functioning). This qualitative study suggests that foster carers' hypervigilant parenting style in establishing, monitoring and maintaining foster children's oral health behaviours may be an adaptive response and an asset. It also highlights the important role that foster 
carers have at a crucial point in the life course of foster children. However, parenting health training programmes have largely ignored foster carers as primary caregivers and have not identified effective health behaviour change approaches for non-traditional families ${ }^{54}$.

While the hyper-vigilant parenting style adopted by foster carers may have been more successful with younger children to establish previously absent tooth brushing habits and to change unhealthy eating, foster carers found teenagers more challenging, particularly when dealing with smoking. Confronting teenagers about smoking caused some tensions and questions about their legitimacy and authority to set rules. The evidence on parenting styles and teenage health behaviours is equivocal. Ditre et al ${ }^{55}$ found that adolescents whose parents had restricted smoking were less likely to start smoking, more likely to quit smoking and smoked fewer cigarettes than teenagers who had no parental smoking restrictions. Other studies have found no relationship between parenting style and children's foodrelated behaviours ${ }^{56}$, oral hygiene practices ${ }^{57}$ or smoking habits ${ }^{58}$. Foster carers tended to rely on their own resources with little support from other health professionals or social care agencies. The findings from this qualitative study suggest that foster carers may need more support when foster children transition into young adulthood (independent living) from other sectors including general medical practitioners, schools programmes and from dedicated smoking specialist services. Further research could also explore the effectiveness of peer-to-peer smoking interventions involving foster children to support foster carers' supporting roles ${ }^{59}$.

Foster carers encountered tensions with dentists refusing to see young children despite guidance recommending that children first visit the dentist when their first teeth erupt usually between six months and one year of age ${ }^{60,61}$. Other studies have also found that dentists were reluctant to see young children, reporting reasons including lack of training about how to manage young children, perceptions about young children's coping skills and lack of awareness of recommendations ${ }^{62-64}$. Further research is needed to explore dentists' (and the wider dental team's) perceptions of foster children and foster carers and the barriers that could prevent them seeing this at-risk group.

Foster carers also reported frustrations with dentists relaying what they thought were inconsistent messages. That dentists were the primary information source for foster carers demonstrates how important it is for social workers and dentists to understand foster carers' parenting role and the challenges that they face in establishing and maintaining recommended oral health behaviours. This also highlights the need for multidisciplinary working to strengthen the links and communication between dental teams, social workers and foster carers. One of the outcomes of this project was the development of a tailor-made oral health resource titled the " 10 key questions for foster carers' oral health booklet." This booklet addressed the most common questions raised by foster carers during 
the focus groups giving evidence-based oral health messages ${ }^{65}$. Further work could also consider the need for alternative information sources using social media and web-based material for teenage foster children.

The research team was aware that their life experiences, perspectives about participants and subconscious biases could influence their interpretations. As part of the bracketing process ${ }^{66}$, the focus group facilitator and coders took part in a reflexivity exercise before carrying out the focus groups. This involved writing short personal reflective accounts about their own positive and negative family experiences and perceptions about parenting and foster children. These were then shared to trigger a discussion about how their perspectives might affect how they questioned and responded to the participants during the focus groups and how these conscious and subconscious biases could influence the data analysis and interpretation. During the data analysis, the researchers also reviewed the recorded memos and observation notes. This reflexivity process allowed the researchers to explicitly recognise and acknowledge their preconceptions and biases. It also helped to establish the confirmability of the findings reflecting the participants' (insider or emic) perspectives and not the researchers' (outsider) perspectives ${ }^{67}$. The time spent immersed in the field engaging with foster carers and social workers before, during and after the study helped to build rapport and allowed the foster carers to be candid about their positive and negative fostering experiences. The findings were also shared with the foster carers (member checking), adding credibility to the findings.

Despite the novel findings, this study had limitations common to all qualitative studies. One must be cautious about the transferability of the findings of this qualitative study, which captured the experiences of long-term foster carers in Tower Hamlets -an ethnically diverse and deprived inner city area. Readers should view this study in light of their own local context in order to determine the transferability of these findings to their setting ${ }^{68}$. However, the strength of qualitative research is its ability to generate hypotheses to explore in further research; to produce knowledge of real depth, and to identify important public health and social care implications.

In conclusion, this qualitative study provided a "thick description" to show the role of the foster family environment in supporting foster children's oral health and dental care. It demonstrated the key oral health caregiving role played by foster carers and the need for multi-agency working and training to support their role. Further research should focus on better understanding the relationship between foster carers and dentists, and on exploring how to develop evidence-informed, multisectoral oral health improvement interventions to improve foster children's oral health. 


\section{References}

1. United Nations General Assembly. Guidelines for the Alternative Care of Children 2010.

2. Briggs F, Hunt S. Foster Care from a Historical Perspective. Child Aus. 2015;40:316-26.

3. Cameron C, Reimer D, Smith M. Towards a theory of upbringing in foster care in Europe. Eur J Soc Work. 2016;19:152-70.

4. Colton MJ, Williams M. Global perspectives on foster family care. Lyme Regis, Dorset: Russell House; 2006.

5. Courtney M, Flynn RJ, Beaupré J. Overview of out of home care in the USA and Canada. Psychol Interv. 2013;22:163-73.

6. Australian Institute of Health and Welfare. Child protection Australia 2013-14. 2015.

7. Statistics Canada. Families and Households Highlight Tables, 2011 Census. Age groups and sex of foster children, for both sexes, for Canada, provinces and territories. 2016.

8. Eurochild. Children in Alternative Care - National Surveys. 2010.

9. Department for Education. Children looked after in England (including adoption) year ending 31 March 2016.

10. Simkiss D. Chapter 11: Looked-after children and young people. In: Department of Health, editor. Annual Report of the Chief Medical Officer 2012, Our Children Deserve Better: Prevention Pays 2013.

11. Keshavarzian G, Family for Every Child. The Place of Foster Care in the Continuum of Care Choices: A Review of the Evidence for Policymakers. 2015.

12. Department for Education. Looked-after children: improving permanence - data pack. 2013.

13. Adoption and Foster Care Analysis and Reporting System. The AFCARS Report. 2016.

14. Martin A, Ford T, Goodman R, Meltzer H, Logan S. Physical illness in looked-after children: a cross-sectional study. Arch Dis Child. 2014;99:103-7.

15. Mooney A, Statham J, Monck E, Chambers H. Promoting the Health of Looked After Children. A Study to Inform Revision of the 2002 Guidance. 2009.

16. Simkiss DE, Stallard N, Thorogood M. A systematic literature review of the risk factors associated with children entering public care. Child Care Health Dev. 2013;39:628-42.

17. Ahrens KR, Garrison MM, Courtney ME. Health Outcomes in Young Adults From Foster Care and Economically Diverse Backgrounds. Pediatrics. 2014;134:1067-74

18. Nutt L. The lives of foster carers : private sacrifices, public restrictions. London: Routledge; 2006.

19. Simkiss D. Outcomes for looked after children and young people. Paediatr Child Health. 2012;22:388-92.

20. Meltzer H, Gatward R, Corbin T, Goodman R, Ford T. The Mental Health of Young People Looked After By Local Authorities in England. Office for National Statistics, 2003.

21. Muirhead V, Wright D. The "Let's Talk about Teeth" Dental Health Project of Looked After Children (LAC) in Tower Hamlets, UK. Summary Report. 2015.

22. Sarri G, Evans P, Stansfeld S, Marcenes W. A school-based epidemiological study of dental neglect among adolescents in a deprived area of the UK. Br Dent J. 2012;213:E17.

23. Poynor M. The Dental Health of Looked after Children. Adopt Fostering. 2004;28:86-8.

24. Williams J, Jackson S, Maddocks A, Cheung WY, Love A, Hutchings H. Case-control study of the health of those looked after by local authorities. Arch Dis Child. 2001;85:280-5.

25. Casey C, Cook-Cottone C, Beck-Joslyn M. An Overview of Problematic Eating and FoodRelated Behavior Among Foster Children: Definitions, Etiology, and Intervention. Child Adolesc Soc Work J. 2012;29:307-22.

26. Castilho AR, Mialhe FL, Barbosa Tde S, Puppin-Rontani RM. Influence of family environment on children's oral health: a systematic review. Jornal de pediatria. 2013;89:116-23.

27. Brown R, Ogden J. Children's eating attitudes and behaviour: a study of the modelling and control theories of parental influence. Health Educ Res. 2004;19:261-71. 
28. de Silva-Sanigorski A, Ashbolt R, Green J, Calache H, Keith B, Riggs E, et al. Parental selfefficacy and oral health-related knowledge are associated with parent and child oral health behaviors and self-reported oral health status. Community Dent Oral Epidemiol. 2013;41:345-52.

29. Adair PM, Pine CM, Burnside G, Nicoll AD, Gillett A, Anwar S, et al. Familial and cultural perceptions and beliefs of oral hygiene and dietary practices among ethnically and socioeconomicall diverse groups. Community Dent Health. 2004;21:102-11.

30. Fuentes MJ, Salas MD, Bernedo IM, Garcia-Martin MA. Impact of the parenting style of foster parents on the behaviour problems of foster children. Child Care Health Dev. 2015;41:70411.

31. Lipscombe J, Farmer E, Moyers S. Parenting fostered adolescents: skills and strategies.

Child \& Family Social Work. 2003;8:243-55.

32. Schofield G, Beek M, Ward E, Biggart L. Professional foster carer and committed parent: role conflict and role enrichment at the interface between work and family in long-term foster care. Child Fam Soc Work. 2013;18:46-56.

33. Blythe SL, Halcomb EJ, Wilkes L, Jackson D. Perceptions of Long-Term Female FosterCarers: I'm Not a Carer, I'm a Mother. Br J Soc Work. 2013;43:1056-72.

34. Rees A, Holland S, Pithouse A. Food in Foster Families: Care, Communication and Conflict. Child Soc. 2012;26:100-11.

35. Children Act 1989: Chapter 41, (1989).

36. Szilagyi MA, Rosen DS, Rubin D, Zlotnik S, Szilagyi MA, Harmon D, et al. Health Care Issues for Children and Adolescents in Foster Care and Kinship Care. Pediatrics. 2015;1142-1166.

37. The Fostering Network. Supporting Placement Planning. Handbook on Delegated Authority. 2011.

38. Isong I, Zuckerman K, Rao S, Kuhlthau K, Winickoff J, Perrin J. Association between parents' and children's use of oral health services. Pediatrics. 2010;125:502-8.

39. Kelly SE, Binkley CJ, Neace WP, Gale BS. Barriers to Care-Seeking for Children's Oral Health Among Low-Income Caregivers. Am J Public Health. 2005;95:1345-51.

40. Owen J, Cooke J. Developing Research Capacity and Collaboration in Primary Care and Social Care. Qual Soc Work. 2004;3:389-410.

41. Reilly F. Making sense of paradigms: the health and social care paradox. Ment Health Pract. 2015;18:38-9.

42. Smith JA. Qualitative psychology: a practical guide to research methods. London: SAGE Publications; 2003.

43. Husserl E. Logical Investigation. New York: Humanities Press; 1970.

44. Furman R, Jackson RL, Downey EP, Shears J. Social Constructivist Practice with Youth. Child Adolesc Soc Work J. 2003;20:263-75.

45. McDermid S, Holmes L, Kirton D, Signoretta P. The demographic characteristics of foster carers in the UK: Motivations, barriers and messages for recruitment and retention. Childhood Wellbeing Research Centre, 2012.

46. Heptinstall E. Research note. Gaining access to looked after children for research purposes: lessons learned. Br J Soc Work. 2000;30:867-72.

47. Patton MQ. Qualitative Research. Encyclopedia of Statistics in Behavioral Science: John Wiley \& Sons, Ltd; 2005.

48. Palmer M, Larkin M, de Visser R, Fadden G. Developing an Interpretative Phenomenological Approach to Focus Group Data. Qual Res Psychol. 2010;7:99-121.

49. Kvale S, Brinkmann S. InterViews: learning the craft of qualitative research interviewing. Los Angeles: Sage Publications; 2015.

50. Pope C, Mays N. Reaching the parts other methods cannot reach: an introduction to qualitative methods in health and health services research. BMJ. 1995;311:42-5.

51. Gill M. The Possibilities of Phenomenology for Organizational Research. Organ Res Methods. 2014;17:118-37.

52. Patton M. Qualitative research and evaluation methods. Thousand Oaks, California: Sage Publications; 2002. 
53. Department for Education, Department of Health. Promoting the health and well-being of looked after children, Statutory guidance for local authorities, clinical commissioning groups and NHS England. 2015.

54. Everson-Hock ES, Jones R, Guillaume L, Clapton J, Goyder E, Chilcott J, et al. The effectiveness of training and support for carers and other professionals on the physical and emotional health and well-being of looked-after children and young people: a systematic review. Child Care Health Dev. 2012;38:162-74.

55. Ditre JW, Coraggio JT, Herzog TA. Associations between parental smoking restrictions and adolescent smoking. Nicotine Tob Res. 2008;10:975-83.

56. Dabawala S, Suprabha BS, Shenoy R, Rao A, Shah N. Parenting style and oral health practices in early childhood caries: a case-control study. Int J Paediatr Dent. 2016;27:135-144

57. Aleksejuniene J, Brukiene V. Parenting style, locus of control, and oral hygiene in adolescents. Medicina (Kaunas, Lithuania). 2012;48:102-8.

58. de Leeuw RNH, Scholte RHJ, Vermulst AA, Engels R. The Associations of Anticipated Parental Reactions with Smoking Initiation and Progression in Adolescents. Am J Addict. 2013;22:527-34.

59. Leve LD, Harold GT, Chamberlain P, Landsverk JA, Fisher PA, Vostanis P. Practitioner Review: Children in foster care - vulnerabilities and evidence-based interventions that promote resilience processes. J Child Psychol Psychiatry. 2012;53:1197-211.

60. American Academy of Pediatric Dentistry. Policy on Use of a Caries-Risk Assessment Tool (CAT) for Infants, Children, and Adolescents. 2006.

61. Rayner JA. The first dental visit: a UK viewpoint. Int J Paediatr Dent. 2003;13:269-.

62. Pine CM, Adair PM, Burnside G, Nicoll AD, Gillett A, Borges-Yanez SA, et al. Barriers to the treatment of childhood caries perceived by dentists working in different countries. Community Dent Health. 2004;21:112-20.

63. Santos CL, Douglass JM. Practices and opinions of pediatric and general dentists in Connecticut regarding the age 1 dental visit and dental care for children younger than 3 years old. Pediatr Dent. 2008;30:348-51.

64. Stijacic T, Schroth RJ, Lawrence HP. Are Manitoba dentists aware of the recommendation for a first visit to the dentist by age 1 year? J Can Dent Assoc. 2008;74:903.

65. Local Government Association. Healthy futures: supporting and promoting the health needs of looked after children. 2016.

66. Tufford L, Newman P. Bracketing in Qualitative Research. Qual Soc Work. 2012;11:80-96.

67. Gasson S. Rigor in grounded theory research: An interpretive perspective on generating theory from qualitative field studies. In: Whitman ME, Woszczynski AB, editors. The handbook of information systems research Hershey, PA: Idea Group; 2004.

68. Lincoln Y, Guba E. Naturalistic Inquiry. Newbury Park: California: Sage Publications; 1985. 
Table 1. Characteristics of foster carers and the children under their care

\begin{tabular}{ll}
\hline Characteristics & Number \\
\hline Gender of foster carers & 11 \\
Female & 1 \\
Male & \\
Age of foster carers (years) & 4 \\
$45-49$ & 6 \\
$50-59$ & 2 \\
60 years and older & \\
Marital Status & 7 \\
Married & 3 \\
Single & 2 \\
Divorced &
\end{tabular}

Ethnic group

Asian 6

Black African 2

Black Caribbean $\quad 4$

Experience of fostering

2-4 years of experience 1

$5-10$ years of experience 3

10 years and above experience $\quad 8$

Number of children currently being fostered

One child 5

$\begin{array}{ll}\text { Two children } & 4\end{array}$

Three children 3

Age of children currently being fostered (years)

$0-4 \quad 2$

5- 9

$10-15$

16 and older 5 


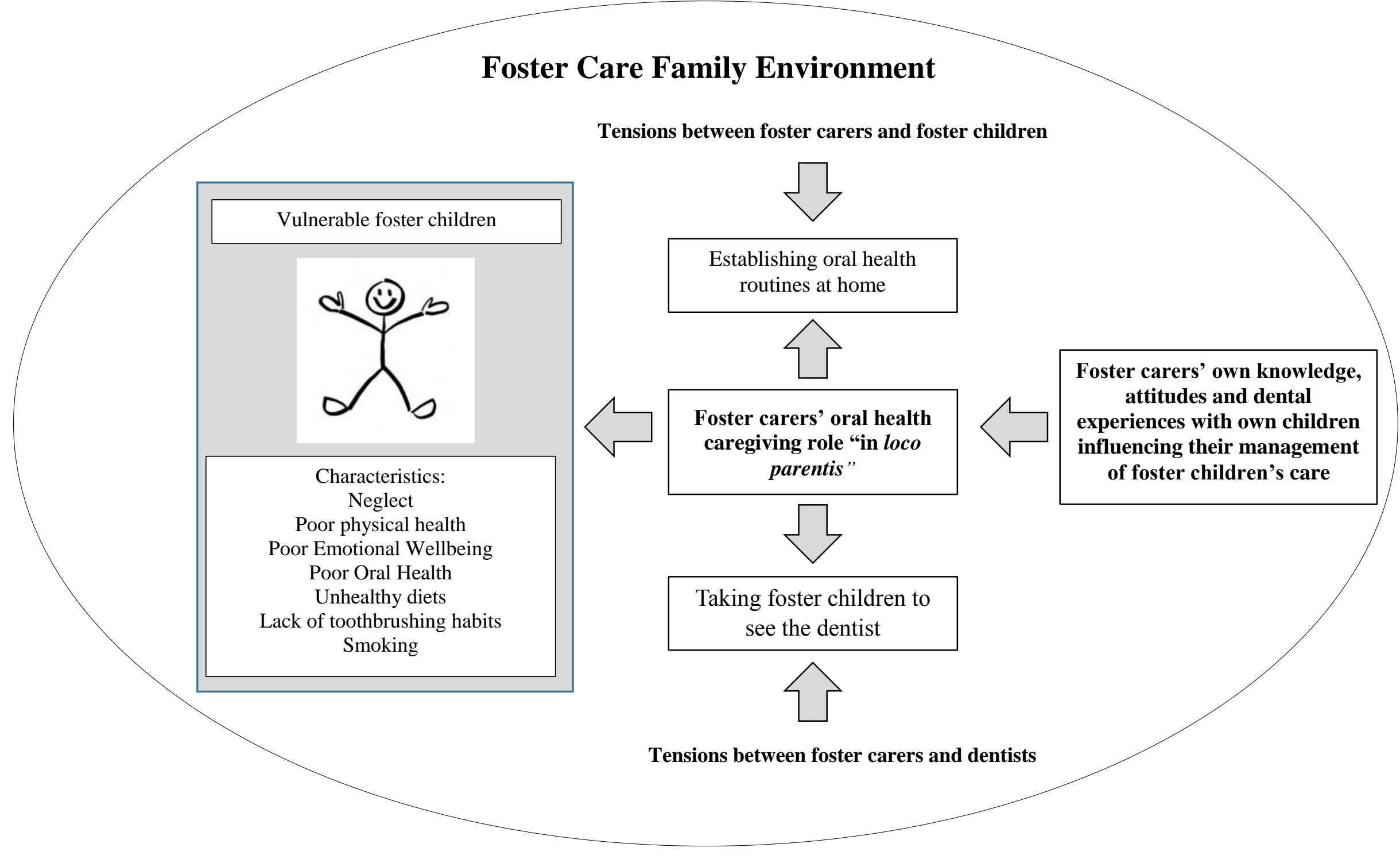


List of all figures and table captions

Table 1. Characteristics of foster carers and the children under their care

Figure 1: Concept map showing the emergent themes related to how foster carers' responded to and managed the oral health of their foster children 